\title{
Thermomechanical process optimization of U-10wt\% Mo - Part 2: The effect of homogenization on the mechanical properties and microstructure
}

\author{
Vineet V. Joshi ${ }^{\text {a,* }}$, Eric A. Nyberg ${ }^{\mathrm{a}}$, Curt A. Lavender ${ }^{\mathrm{a}}$, Dean Paxton ${ }^{\mathrm{a}}$, Douglas E. Burkes ${ }^{\mathrm{a}}$ \\ ${ }^{a}$ Pacific Northwest National Laboratory \\ 902 Battelle Boulevard, Richland, WA 99354 \\ Phone: (001) 509-372-6211, Fax: (001) 509-375-4448
}

\begin{abstract}
In the first part of this series, it was determined that the as-cast U-10Mo had a dendritic microstructure with chemical inhomogeneity and underwent eutectoid transformation during hot compression testing. In the present (second) part of the work, the as-cast samples were heat treated at several temperatures and times to homogenize the Mo content. Like the previous ascast material, the "homogenized" materials were then tested under compression between 500 and $800^{\circ} \mathrm{C}$. The as-cast samples and those treated at $800^{\circ} \mathrm{C}$ for 24 hours had grain sizes of $25-30 \mu \mathrm{m}$, whereas those treated at $1000^{\circ} \mathrm{C}$ for 16 hours had grain sizes around $250 \mu \mathrm{m}$ before testing. Upon compression testing, it was determined that the heat treatment had effects on the mechanical properties and the precipitation of the lamellar phase at sub-eutectoid temperatures.
\end{abstract}

KEYWORDS: U-10wt\% Mo, Mechanical Properties, Microstructure, Compression Testing

\section{Introduction}

Thermomechanical processing and modeling of metals and alloys require fundamental understanding of the initial and the intermediate or developing microstructures and their corresponding mechanical properties. The eventual properties and performance of the end product is normally a function of the initial microstructure and the processing route employed. Development of uranium with $10 \mathrm{wt} \%$ molybdenum (U-10Mo) fuel plate for research reactors is

${ }^{*}$ Corresponding author

Email address: vineet.joshi@pnnl.gov (Vineet V. Joshi) 
currently underway and several processing techniques/routes are being evaluated for fabrication $[1,2]$. Microstructure-based finite element modeling can help predict the alloy's behavior under different processing conditions and reduce the amount of experimentation needed to develop the processing conditions required for high quality fuel. In order to develop robust models, accurate mechanical properties and microstructures must be fed into the finite element constitutive relation for a particular set of conditions [3]. For a finite element modeling hot-working prediction, in particular, the flow stress must be tested over a range of expected strain rates and temperatures. There is very limited mechanical data available in the literature for the U-10Mo alloy for the expected process conditions (temperatures and strain rates). Generally, that which is available, such as Saller et al. and McGeary $[4,5]$, is not in a relevant composition or processing condition, making precise model predictions challenging.

In the first part of this work [6], it was observed that the as-cast material had a dendritic microstructure and had chemical inhomogeneity. Although the entire structure was primarily metastable $\gamma$ phase, the compression-test temperature exposure used for this study resulted in eutectoid decomposition to the lamellar $\alpha$ plus $\gamma^{\prime}$. Such a transformation may be detrimental for processing, and possibly to its in-reactor performance. It has been determined earlier by several authors (Sinha et al. 2010 [7-9], Bostrom and Halteman 1956 [10], Hofman and Meyer 1998 [11]) that the time required to transform a completely homogeneous structure into the lamellar structure is about 10 hours at approximately $500^{\circ} \mathrm{C}$. In order for the material to be homogenized and metastable $\gamma$, the U-10Mo must be heat treated in the $\gamma$ phase and cooled quickly enough to avoid transformation to the equilibrium $\alpha$ plus $\gamma^{\prime}$. In the current work, the effect that the homogenization heat treatment had on the high-temperature mechanical properties and 
microstructure of the U-10Mo alloy was evaluated. Various homogenization times and temperatures were studied, ranging between 800 and $1000^{\circ} \mathrm{C}$ and 4 to 48 hours.

\section{Experimental}

\subsection{Materials and compression testing}

The pin-cast U-10Mo samples used in the current work were obtained from Idaho National Laboratory and the details of the chemistry and compression testing of the castings can be found in the earlier part of this series [6].

\subsection{Homogenization heat treatment}

The homogenization heat treatments were conducted in a high-temperature furnace (MTI Model VBF-1200X) operated under inert atmosphere using high-purity bottled argon. The atmospheric flow rate was maintained at approximately $11.7 \times 10^{-6} \mathrm{~m}^{3} / \mathrm{s}$. The samples were wrapped in $\mathrm{Zr}$ foil and placed in an alumina crucible (with lid). The furnace was evacuated and backfilled with argon three times; then continuous argon flow was established. The heating cycle was a $10^{\circ} \mathrm{C} /$ minute ramp rate to $350^{\circ} \mathrm{C}$, then a 15 -minute hold, then another ramp at the same rate to the homogenization temperature for the required amount of time, i.e., $4-48$ hours. This was followed by furnace cooling under flowing argon back to room temperature. The cooling rate was approximately $25^{\circ} \mathrm{C} /$ minute.

\subsection{Microstructural characterization and phase analysis}

To compare the effect of strain to the exact thermal profiles, both as-cast samples and samples that were heat treated with the same heating and cooling rate used in the compression test were strained to $0.4 \mathrm{~cm} / \mathrm{cm}$ before microstructural characterization. All microstructural samples were characterized transverse to the compression direction, at the approximate midpoint (5 to $6 \mathrm{~mm}$ from the ends). The actual strain in the samples used for microstructural 
characterization was close to $0.4 \mathrm{~cm} / \mathrm{cm}$ based on axial compression. For the microstructural analysis, the compression-tested samples were cold mounted in an epoxy resin and then crosssectioned at approximately half the length or at the region that experienced maximum strain. The mounted samples were successively polished down to 600 grit with silicon carbide polishing papers, then further polished using $6 \mu \mathrm{m}$ and $1 \mu \mathrm{m}$ diamond slurries, followed by a final colloidal silica polish. Upon polishing, the samples were carbon coated for scanning electron microscopy (SEM) analysis. The detailed technique used to prepare the samples for characterization can be found in a previous report [12]. Microstructural characterization was performed using an optical microscope as well as using a JEOL JSM-7600F SEM equipped with an Oxford Instruments X-Max 80 energy dispersive spectroscopy (EDS) detector. The EDS analysis was performed using the INCA Microanalysis Suite software, version 4.15. Grain size

analysis, quantitative image analysis, and carbide form and morphology analysis were conducted on the SEM-backscattered electron (BSE) images at 100× and 500× magnification and were analyzed using ImageJ software. Grain size was measured manually by lineal analysis. Quantitative image analysis and carbide form identification were performed using ImageJ by adjusting the threshold of the area of interest, and after which they were processed using the automated analysis tool.

\section{Results}

\subsection{Homogenization: microstructure of the as-cast U-10Mo}

In order to determine the heat-treatment time and temperature required to transform the cast structure to the homogenized structure, a series of heat treatments were conducted. Please refer to the previous paper in the series [6] for a detailed discussion on the microstructure of the ascast U-10Mo sample. Samples were homogenized at $800^{\circ} \mathrm{C}$ for $4,8,16,24$ and 48 hours, and 
also at $1000^{\circ} \mathrm{C}$ for 16 hours [13]. The chemical homogeneity was determined based on the BSE atomic number contrast ( $\mathrm{Z}$ contrast) and EDS line scans. Fig. 1 shows the effect of heat treatment on the homogenization. Details of the homogenization heat-treatment analysis are not included here; however, based on the BSE Z contrast and EDS line scans, it was determined that treatments at $800^{\circ} \mathrm{C}$ for 24 hours and $1000^{\circ} \mathrm{C}$ for 16 hours showed the most complete homogenization. It should also be noted that the grain size for the sample homogenized at $800^{\circ} \mathrm{C}$ for 24 hours was $10-30 \mu \mathrm{m}$, whereas the samples homogenized at $1000^{\circ} \mathrm{C}$ for 16 hours had grain sizes between 200 and $250 \mu \mathrm{m}$. The other important aspect was that the carbides for the samples homogenized at $1000^{\circ} \mathrm{C}$ for 16 hours were spherical with diameters up to $8 \mu \mathrm{m}$ in some cases and were located within the grain, unlike those treated at $800^{\circ} \mathrm{C}$ for 24 hours, in which virtually all carbides were found at the grain boundaries. The shape change and coarsening of the spherical carbides can likely be associated with typical Ostwald ripening. The carbides present in the U-10Mo samples homogenized at $800^{\circ} \mathrm{C}$ for 24 hours had an aspect ratio of 1:5, with the largest diameter being approximately 1-2 $\mu \mathrm{m}$, and were located primarily at the grain boundaries (Fig. 2a, Fig. 2b). The floret-like structures (Fig. 2a) were typically remnants of yttrium oxide used as a parting agent in the die molds. Some of the carbides were transformed into a spherical shape due to Ostwald ripening and attained a stable spherical carbide structure. Although the shape of the carbides changed, the volume of the carbides remained constant (Fig. 2b) and on the order of 2 volume percent, based on image analysis. Given the Mo homogeneity, the materials heat treated at $800^{\circ} \mathrm{C}$ for 24 hours and $1000^{\circ} \mathrm{C}$ for 16 hours were tested under compression at different temperatures at a strain rate of $6.5 \times 10^{-4} \mathrm{~s}^{-1}$ and the data was compared to that of the previously tested as-cast samples. 


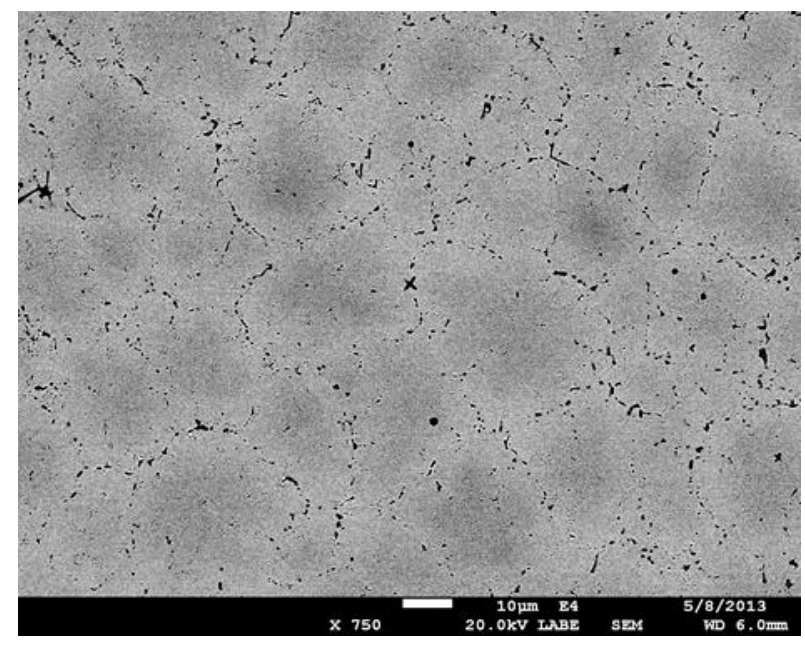

(a)

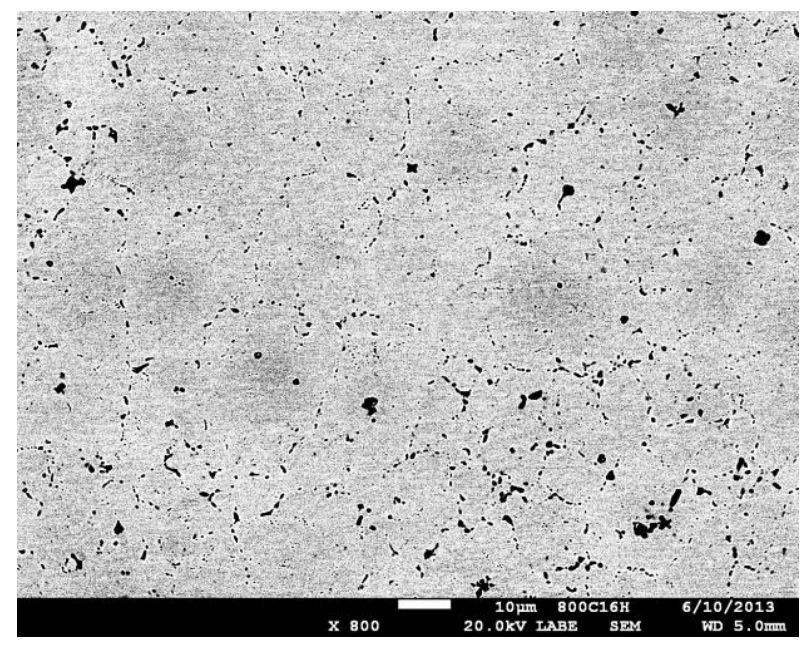

(c)

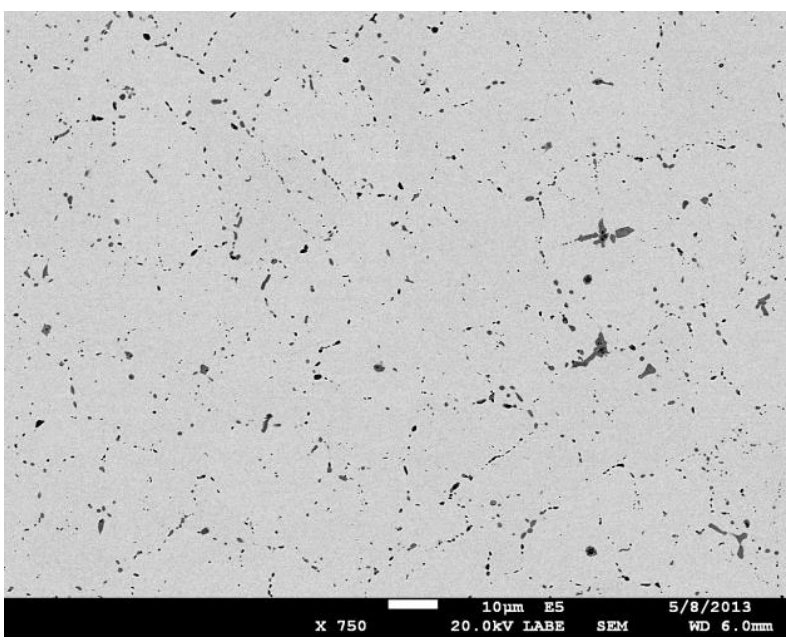

(e)

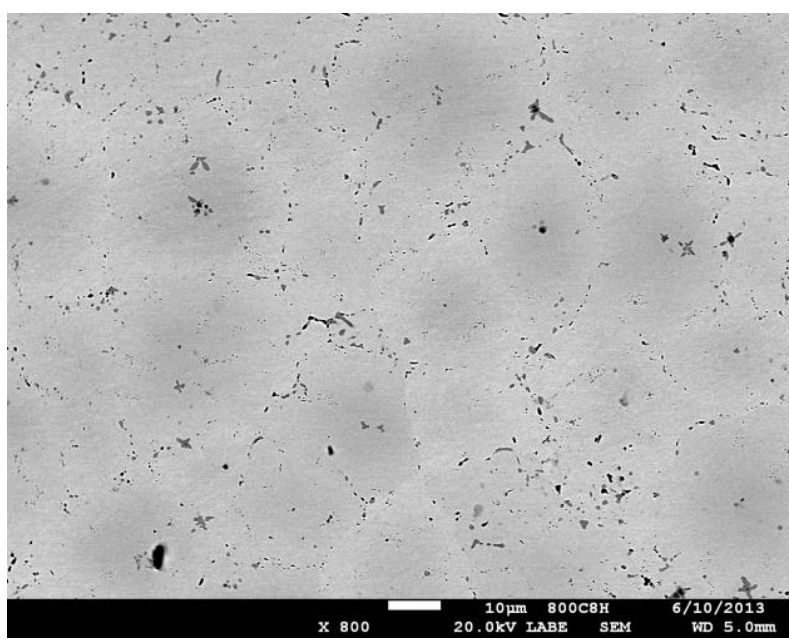

(b)

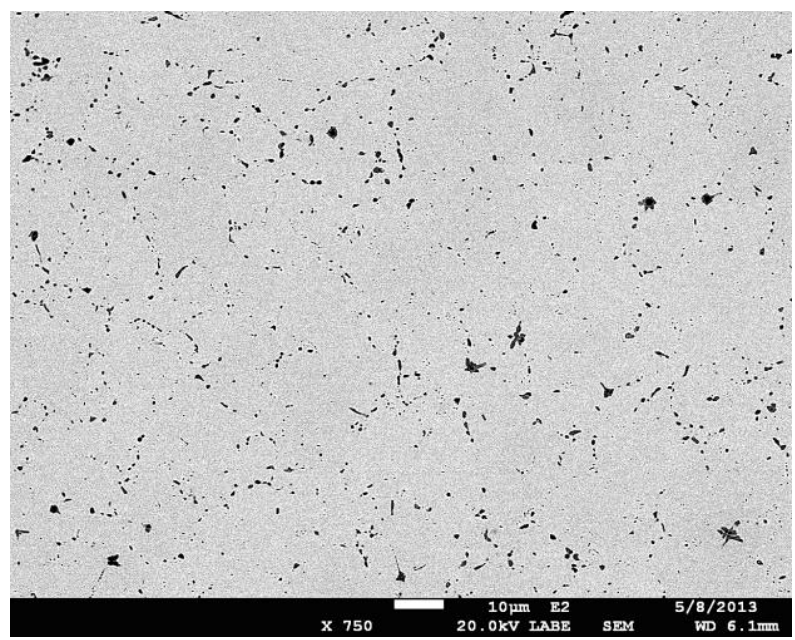

(d)

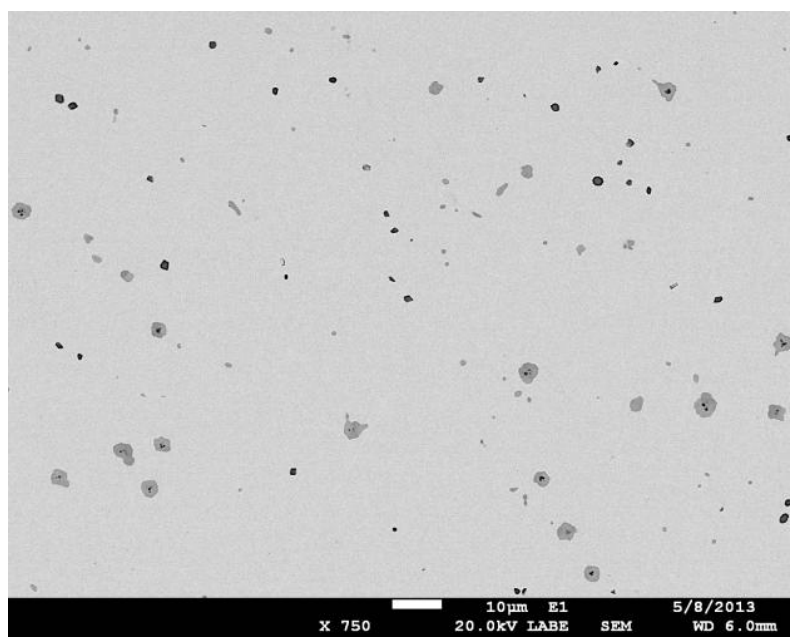

(f)

Fig. 1. BSE-SEM images of the heat-treated U-10Mo samples: (a-d) homogenized at $800^{\circ} \mathrm{C}$ for 4, 8, 16, 24 and 48 hours, respectively; (e) homogenized at $1000^{\circ} \mathrm{C}$ for 16 hours. 
Corresponding grain size was measured as 25-30 $\mu \mathrm{m}$ for (a-c), bimodal 10-30 $\mu \mathrm{m}$ for (d-e) and approximately $200-250 \mu \mathrm{m}$ for (f). The intensity of the dark gray areas decreases as the homogenization time and temperature increases.

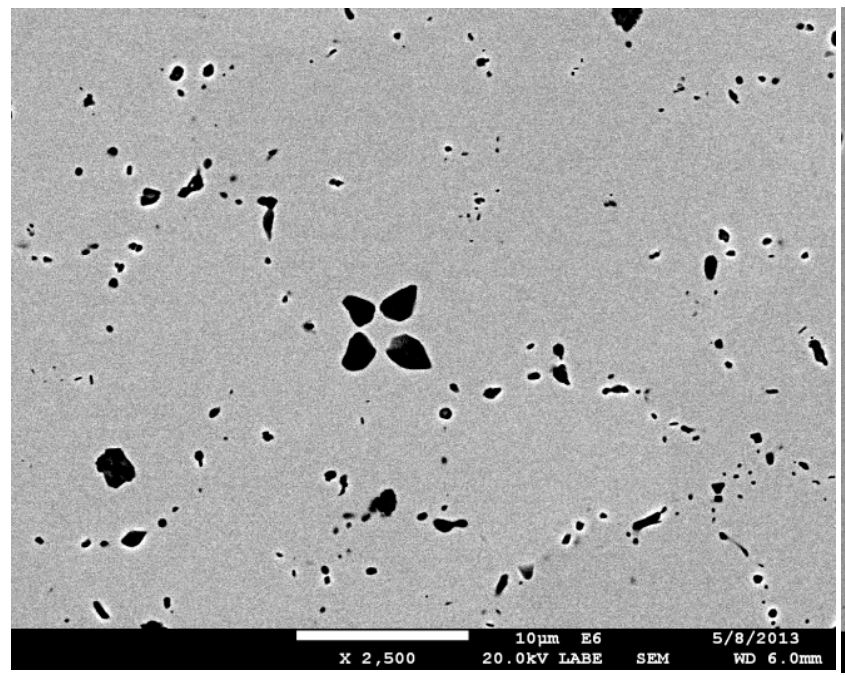

(a)

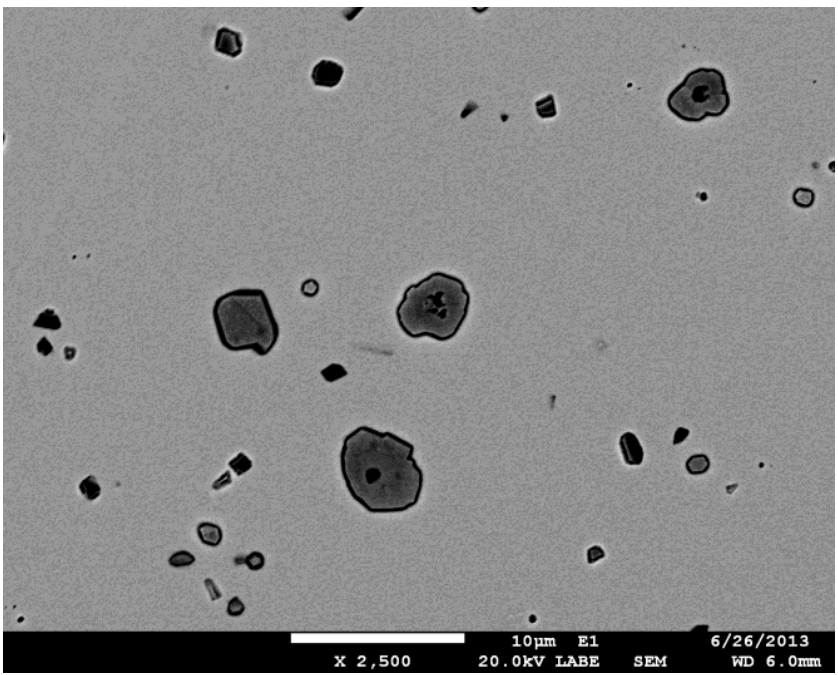

(b)

Fig. 2. High-magnification BSE-SEM images of the samples homogenized (a) at $800^{\circ} \mathrm{C}$ for 24 hours and (b) at $1000^{\circ} \mathrm{C}$ for 16 hours.

\subsection{Mechanical properties (compression testing)}

Due to the test system configuration, the desire to measure flow stress at high strains, and the reactivity of the U-10Mo, compression tests were conducted without a strain gauge/extensometer or other methods to evaluate strain/deformation (e.g., digital image correlation). Therefore, compressive load was measured as a function of the cross-head displacement and then used to calculate stress and strain. To increase the accuracy of the stressstrain data, displacements were later adjusted to compensate for the compliance (elasticity) of the testing system. The compliance of the system was determined by conducting compression tests using the test fixture without specimens, at representative test temperatures, and determining load displacement. To calculate strain, the displacement within the system, without a sample, as 
a function of load was subtracted from the actual test data. Henceforth, all the stress-strain data reported in this report will be compliance adjusted as described previously [6].

Compressive true-stress/true-strain curves for each test temperature, for the as-cast and the samples homogenized at $800^{\circ} \mathrm{C}$ for 24 hours and at $1000^{\circ} \mathrm{C}$ for 16 hours are provided in Fig. 3 . Fig. 4 shows the flow stress at $10 \%$ strain as a function of test temperature. Below the eutectoid temperature $\left(\sim 550^{\circ} \mathrm{C}\right)$ all three samples showed strain hardening and followed similar trends.

Above the eutectoid temperature (at approximately half the melting point $\left(\mathrm{T}_{\mathrm{m}}\right)$ ), i.e., in the single, $\gamma$-phase field, the as-cast samples and those homogenized at $800^{\circ} \mathrm{C}$ for 24 hours follow similar trends. The stress-strain curves exhibited the stress drop (negative strain hardening) normally associated with dynamic crystallization observed in the body-centered cubic (BCC) alloys [14]. It should be noted that the samples heat treated at $1000^{\circ} \mathrm{C}$ for 16 hours had higher flow stress at large strains as compared to the other samples. The trend in the yield stress/flow stress above the eutectoid temperature of all the samples compression tested is linear, as shown in Fig. 4. The samples homogenized at $1000^{\circ} \mathrm{C}$ for 16 hours exhibit a perfectly plastic behavior at strains larger than $10 \%$ (strain-hardening exponent $n=0$ ) whereas the as-cast samples and those homogenized at $800^{\circ} \mathrm{C}$ for 24 hours have $\mathrm{n}$ values of $-0.2,-0.12$, and 0.17 at 600,700 and $800^{\circ} \mathrm{C}$, respectively. 


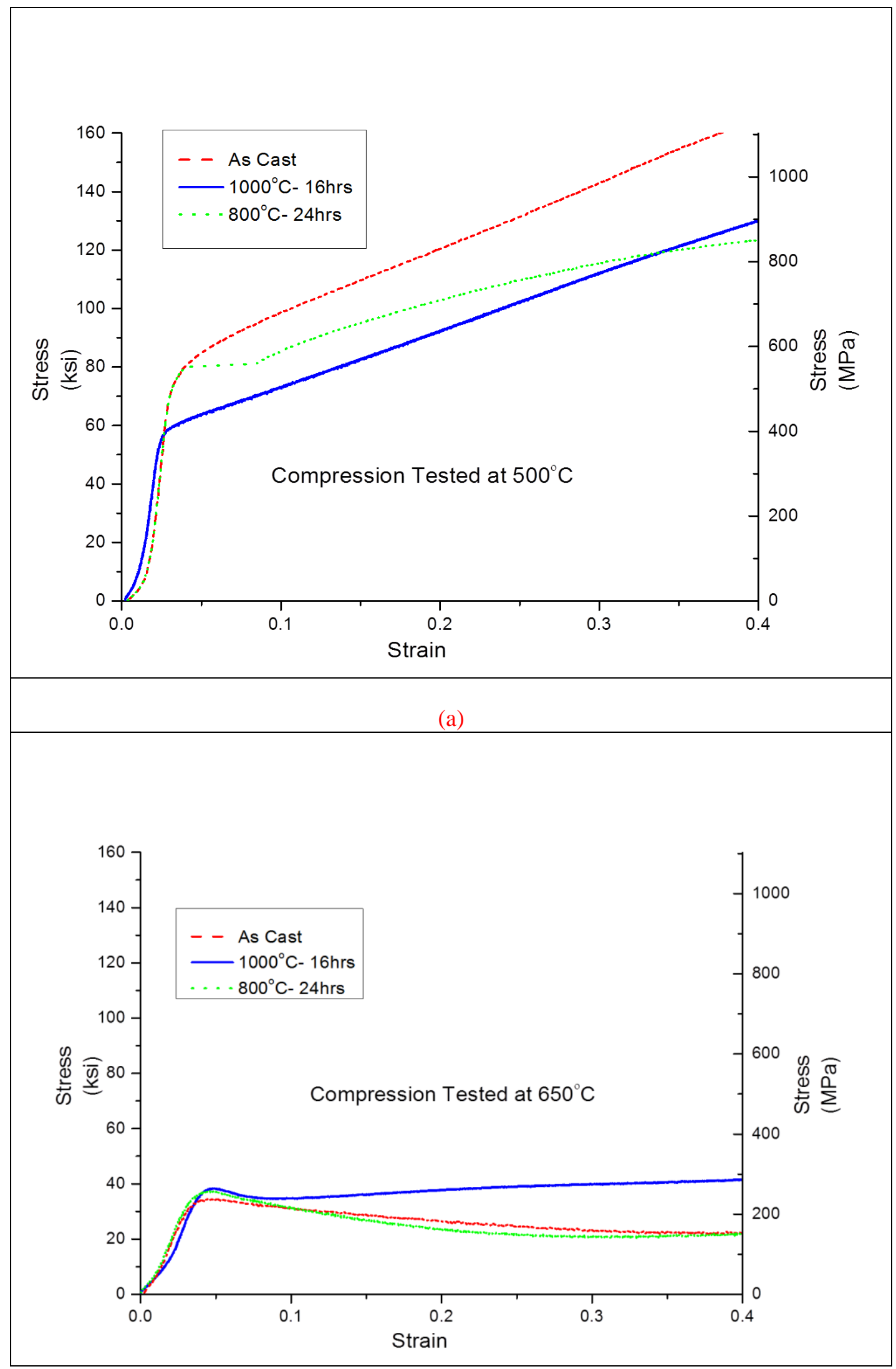




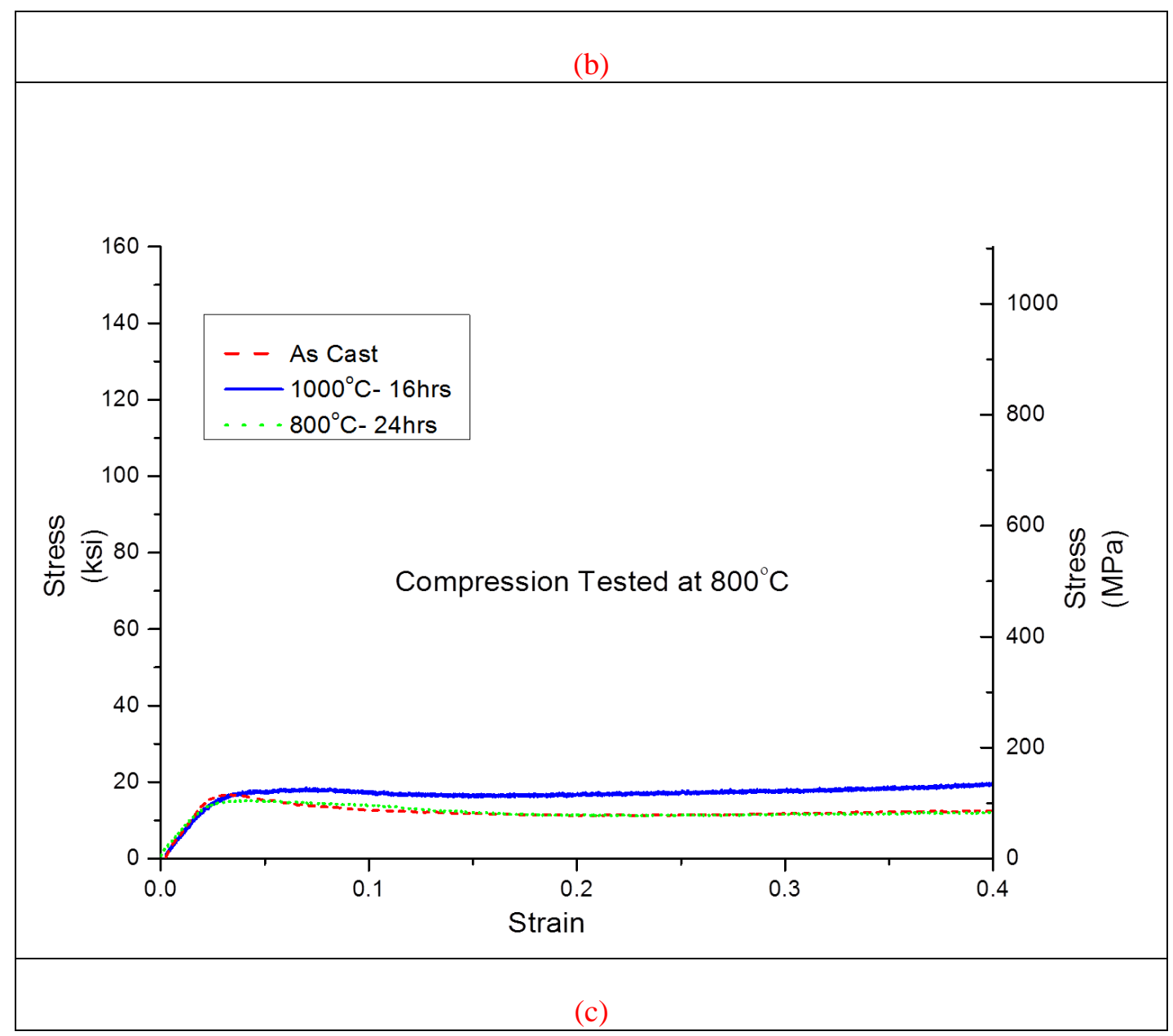

Fig. 3. Stress-strain curves of the U-10Mo samples that were as-cast, homogenized at $1000^{\circ} \mathrm{C}$ for 16 hours, and homogenized at $800^{\circ} \mathrm{C}$ for 24 hours as a function of temperature. (a) compression tested at $500^{\circ} \mathrm{C} \mathrm{(b)} \mathrm{Compression} \mathrm{tested} \mathrm{at} 650^{\circ} \mathrm{C}$ and (c) Compression tested at $800^{\circ} \mathrm{C}$. 


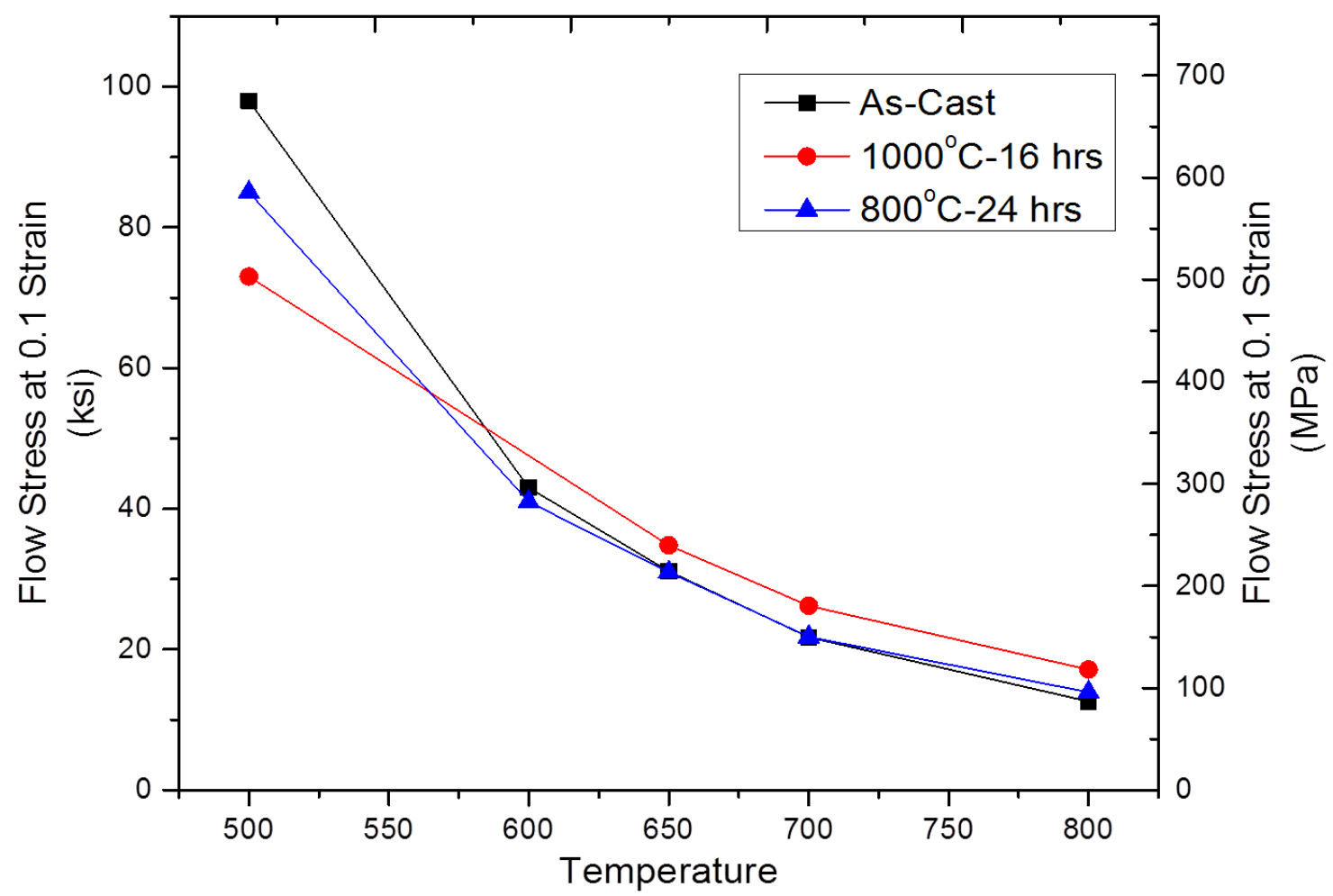

$\left({ }^{\circ} \mathrm{C}\right)$

Fig. 4. Flow stress at $10 \%$ strain as a function of test temperature and homogenization conditions.

\subsection{Microstructure of compression-tested samples}

\subsubsection{Samples compression tested at $500^{\circ} \mathrm{C}$}

The effect of compression testing at $500^{\circ} \mathrm{C}$ (below the eutectoid temperature) on the as-cast samples and those homogenized at $800^{\circ} \mathrm{C}$ for 24 hours and at $1000^{\circ} \mathrm{C}$ for 16 hours is shown in Fig. 5. The BSE-SEM images of the compression-tested as-cast sample revealed a microstructure similar to the cast microstructure (dendrites, interdendritic regions, carbon-rich needles and oxygen-rich phases) and are shown in Fig. 5a and Fig. 5b. The grain size increased to between 50 and $60 \mu \mathrm{m}$, approximately two times that of the as-cast sample, likely due to the pancaking of the grains under compressive strain. Apart from the aforementioned phases, a cellular/lamellar 
structure was also observed in these samples along the grain boundaries. Some of these lamellae had a distorted structure, likely due to the strain. The interlamellar spacing was less than $100 \mathrm{~nm}$ and hence it was difficult to discern the chemistry of the individual phases via EDS. In the case of the samples heat treated at $800^{\circ} \mathrm{C}$ for 24 hours, it was observed in the BSE-SEM images (Fig. 5c, Fig. 5d) that a fine structure precipitated along the grain boundaries uniformly, indicative of the recrystallized grains. The grain size increased by $5-10 \mu \mathrm{m}$ and the carbides were present at the grain boundaries among the recrystallized grains. Fig. 5e and Fig. 5f show the microstructure of the sample that was homogenized at $1000^{\circ} \mathrm{C}$ for 16 hours upon compression testing at $500^{\circ} \mathrm{C}$. Unlike the previous two samples, this sample did not show the presence of the lamellar/ recrystallized structure. However, the carbides in this case fractured along the compression axis. The grain size also increased as the compression progressed, again likely due to strain rather than grain growth.

\subsubsection{Samples compression tested at $650^{\circ} \mathrm{C}$}

The effect of compression testing at $650^{\circ} \mathrm{C}$ (above the eutectoid temperature) on the as-cast samples and on the samples homogenized at $800^{\circ} \mathrm{C}$ for 24 hours and at $1000^{\circ} \mathrm{C}$ for 16 hours is shown in Fig. 6. As compared to those tested below the eutectoid temperature, the samples tested above the eutectoid temperature showed significant lamellar structure transformation at $650^{\circ} \mathrm{C}$ in the as-cast microstructure. The total volume fraction of the lamellar structure in this case is nearly $14 \%$. The interlamellar spacing for the lamellar phase was approximately $100 \mathrm{~nm}$. The lamellae seem to have precipitated along the grain boundaries in the molybdenum-lean regions. The strain did not distort the structure in these regions and the uniform lamellar structure was retained, likely indicating a softer matrix in comparison to the $500^{\circ} \mathrm{C}$ sample, where distortion was observed. 
For samples homogenized at $800^{\circ} \mathrm{C}$ for 24 hours and compression tested at $650^{\circ} \mathrm{C}$, the BSESEM images revealed a hazy phase along the grain boundaries and a very small amount of lamellar structure (Fig. 6c and Fig. 6d). This hazy phase is representative of dynamically recrystallized grains under high magnification, whereas the lamellar structure was only present in a small number of discrete locations (Fig. 7). The EDS analysis showed the lamellar phase prominently (Fig. 7), whereas the recrystallized phases were not discernable under the conditions observed. In order to verify the recrystallization and determine the recrystallized grain structure, an in-depth characterization technique such as transmission electron microscopy would be needed but was beyond the scope of the current work. The carbides seem to have retained their position along the grain boundaries. For the samples homogenized at $1000^{\circ} \mathrm{C}$ for 16 hours and compression tested at $650^{\circ} \mathrm{C}$, the microstructure was similar to that of the samples compression tested at $500^{\circ} \mathrm{C}$; however, in this case the carbides seem to have retained their form and no fracture was observed. Despite the dynamic recrystallization observed in the stress-strain curve, the formation of new grains was not evident in the microstructural characterization. 


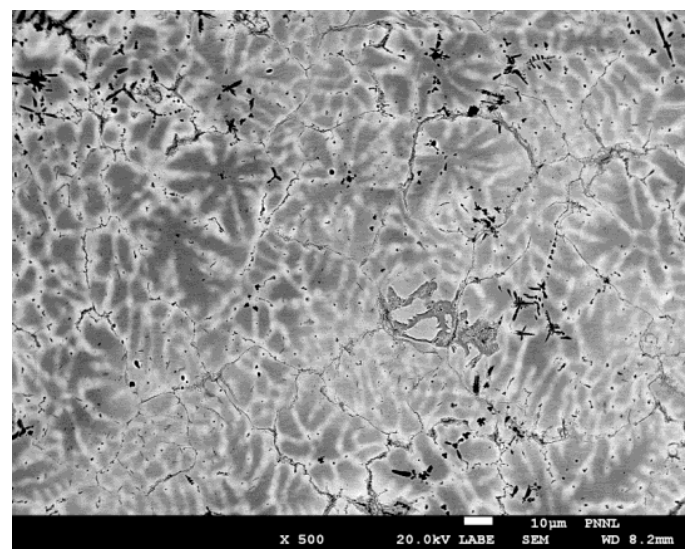

(a)

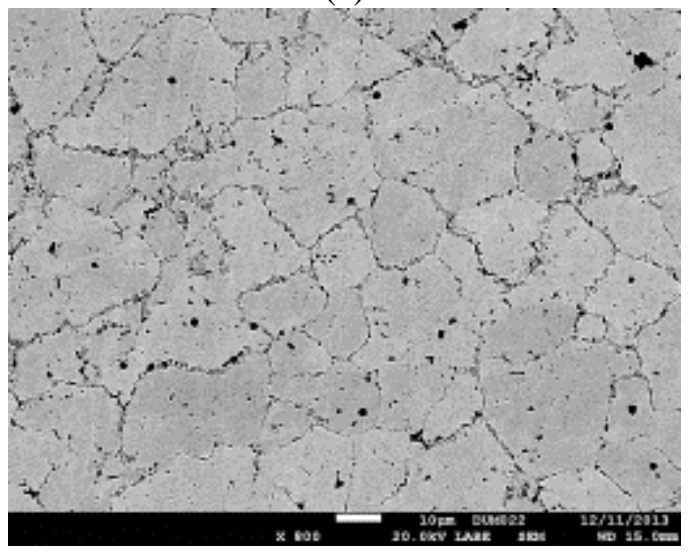

(c)

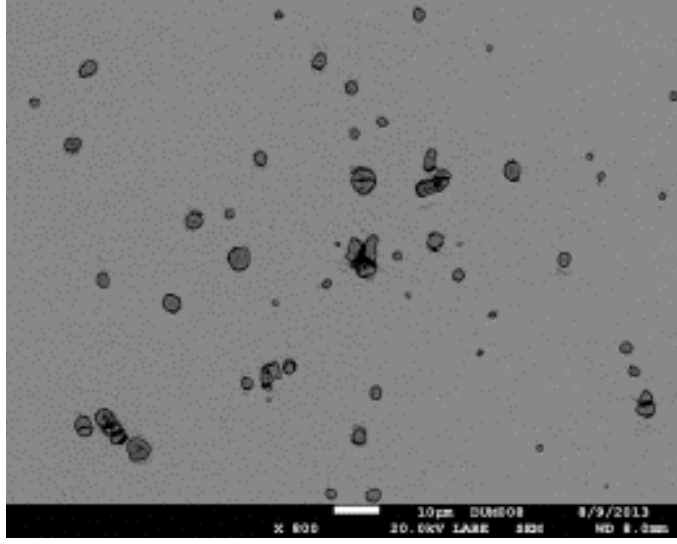

(e)

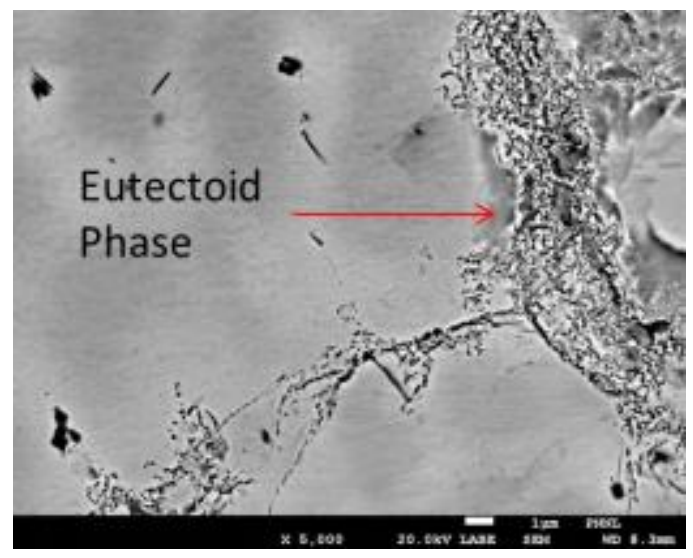

(b)

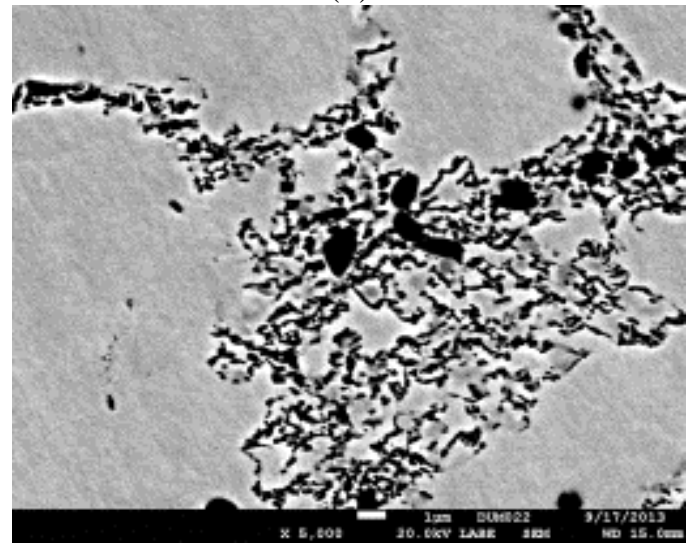

(d)

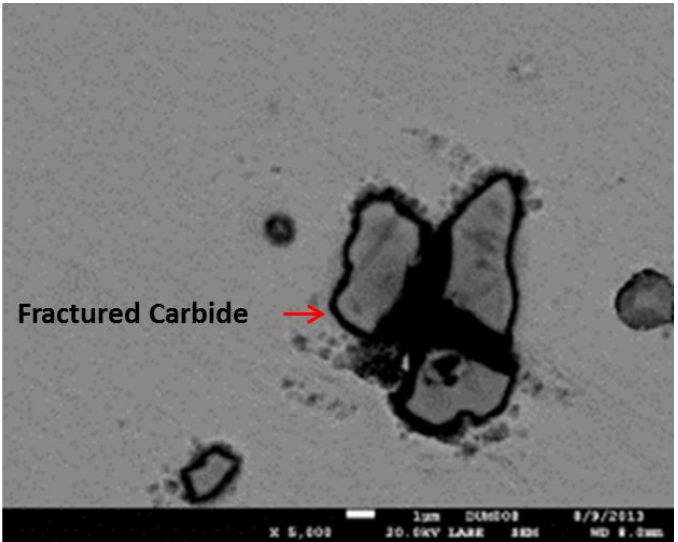

(f)

Fig. 5. BSE-SEM images of the samples after compression testing at $500^{\circ} \mathrm{C}$ : as-cast (a) at $500 \times$, (b) 5000x; the samples homogenized at $800^{\circ} \mathrm{C}$ for 24 hours (c) at $500 \times$, (d) $5000 x$; and those homogenized at $1000^{\circ} \mathrm{C}$ for 16 hours (e) at $500 \times$, (f) $5000 \times$. 


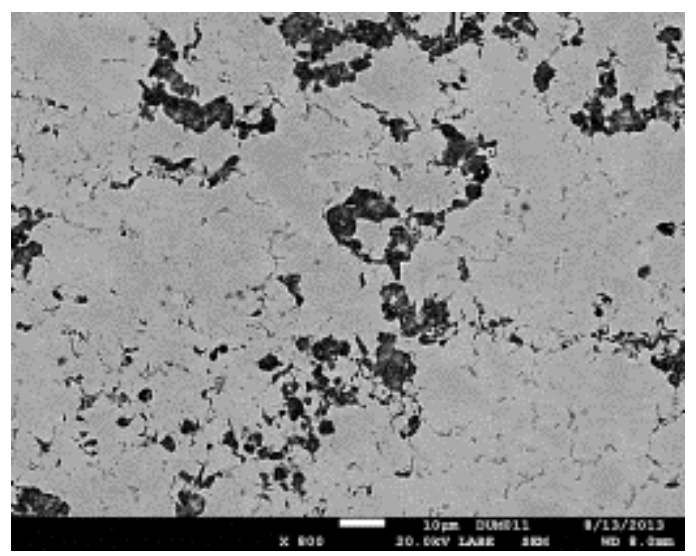

(a)

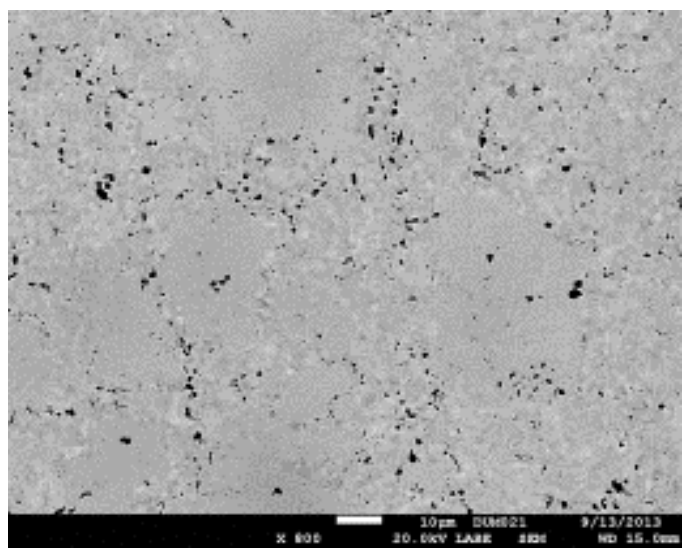

(c)

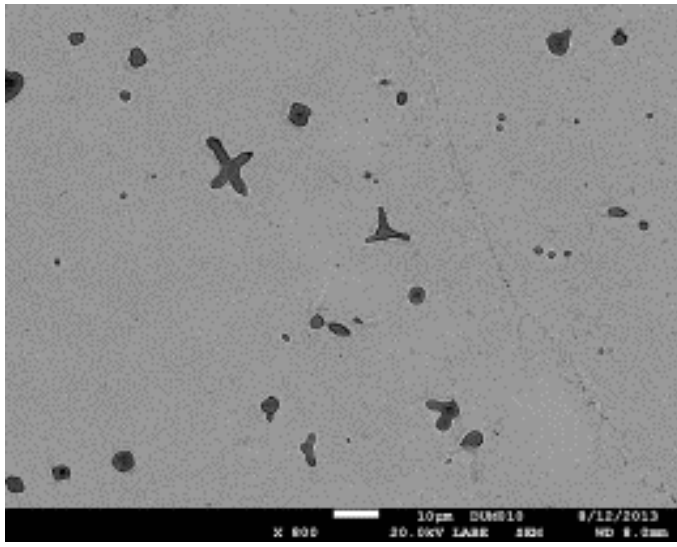

(e)

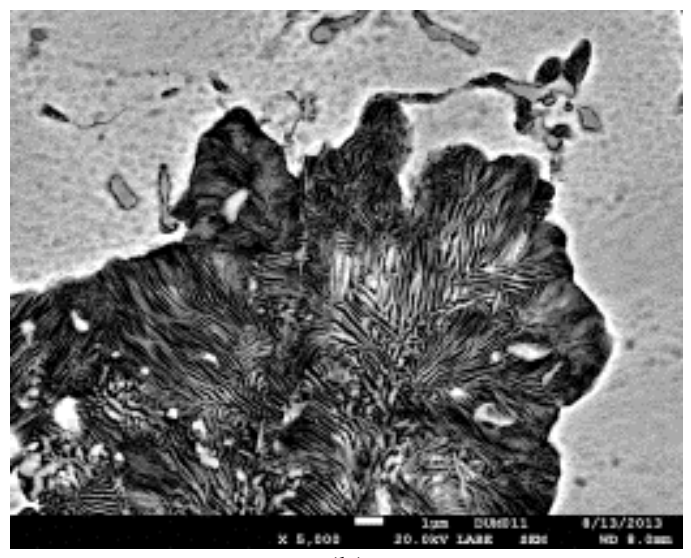

(b)

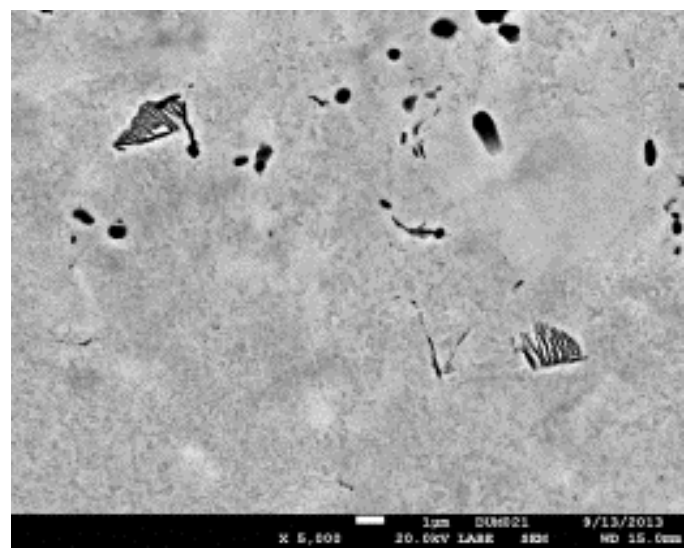

(d)

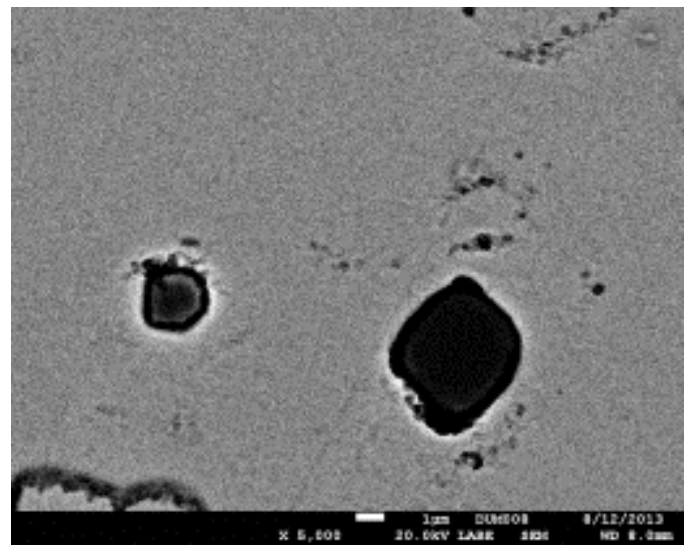

(f)

Fig. 6. BSE-SEM Image of the samples after compression testing at $650^{\circ} \mathrm{C}$ : as-cast (a) at $800 \times$, (b) $5000 \times$; the samples homogenized at $800^{\circ} \mathrm{C}$ for 24 hours (c) at $800 \times$, (d) $5000 x$; and $1000^{\circ} \mathrm{C}$ for 16 hours (e) at $800 \times$, (f) $5000 \times$. 


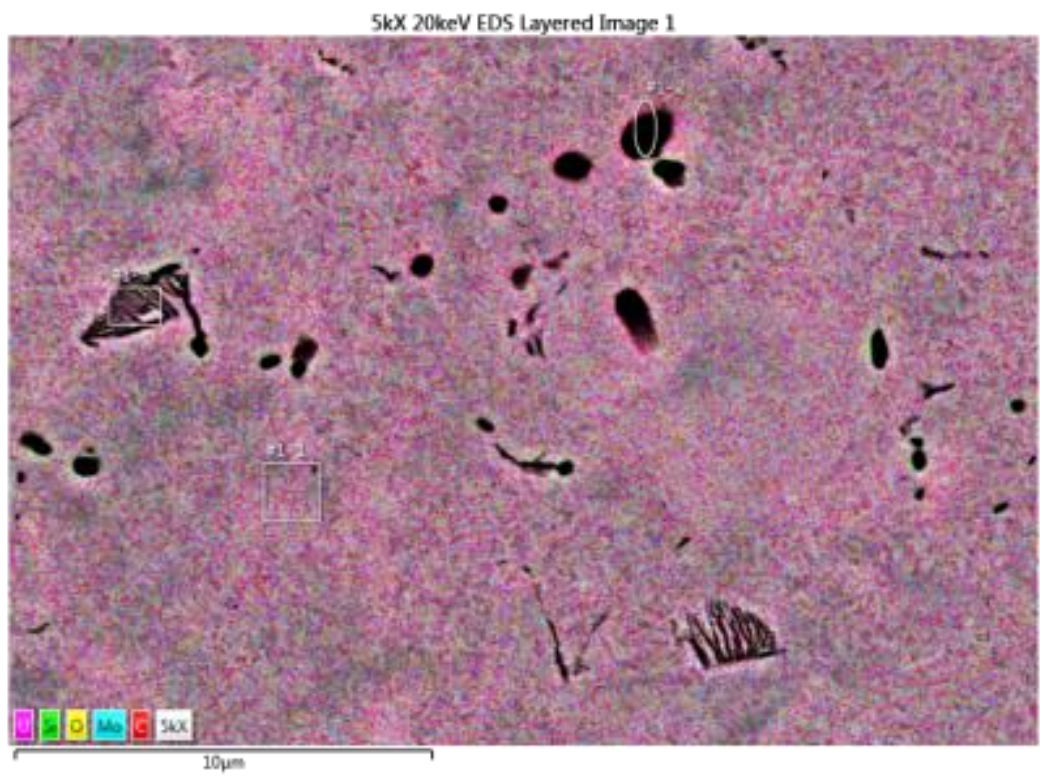

Fig. 7. A composite EDS map of the sample homogenized at $800^{\circ} \mathrm{C}$ for 24 hours and after compression testing at $650^{\circ} \mathrm{C}$.

\subsubsection{Samples compression tested at $800^{\circ} \mathrm{C}$}

The BSE-SEM images of the as-cast sample that was compression tested at $800^{\circ} \mathrm{C}$ are shown in Fig. 8a and Fig. 8b, which revealed significant homogenization of the microstructure as compared to the previous as-cast compression-tested samples. The dendritic structure (dark gray areas imaged by the $\mathrm{Z}$ contrast in the BSE mode) is no longer clearly visible but appears as a hazy structure in some of the grains, indicating nearly complete homogenization. The grain size in these as-tested samples increased by six times, to $150 \mu \mathrm{m}$, from that in the as-cast structure. Nearly $50 \%$ of the grains were homogenized completely and no segregation was observed. In these samples, as compared to the samples tested at 500 and $700^{\circ} \mathrm{C}$, the lamellar phases were finer, as shown in Fig. 8b. The uranium-rich carbides and oxides of yttrium were present and had retained their form and shape. These precipitates were homogeneously dispersed along the entire cross-section, indicating that grain growth had occurred beyond the original carbide-rich boundaries. 
Microstructural change from compression testing at $800^{\circ} \mathrm{C}$ of the sample homogenized at $800^{\circ} \mathrm{C}$ for 24 hours is shown in Fig. $8 \mathrm{c}$ and Fig. 8 d. It was observed that the hazy molybdenum submicron-scale segregation was retained along the grain boundaries and the carbides also retained their form and shape; however, the lamellar phase was not visible in this case. It is also noteworthy that the grain size increased by nearly 50\%. In comparison to the previous compression-tested samples with the same homogenization heat treatment, this sample had a far more uniform microstructure and exhibited stress-induced homogenization. In the case of the samples compression tested at $800^{\circ} \mathrm{C}$ that were homogenized at $1000^{\circ} \mathrm{C}$ for 16 hours, the microstructure was similar to that of the previous sample (Figs. 6e, 6f) as shown in Fig. 8e. It should be noted that the grain boundary movement is impeded by the carbide particles, as shown by the bowed grain boundary in the bottom left of Fig. 8e. 


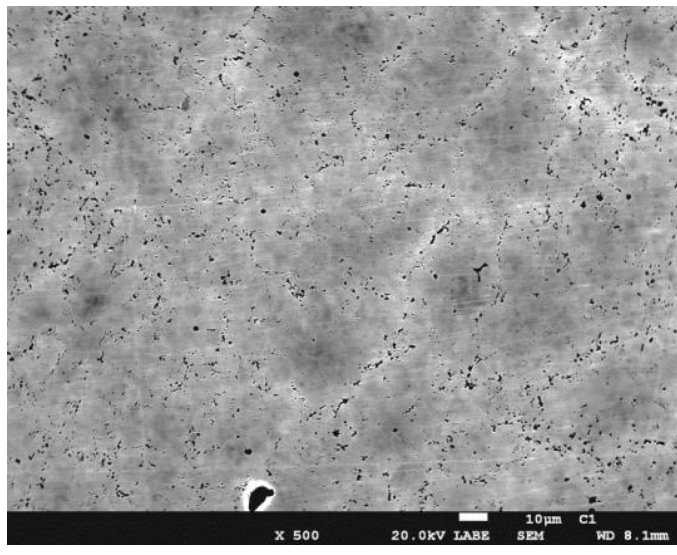

(a)

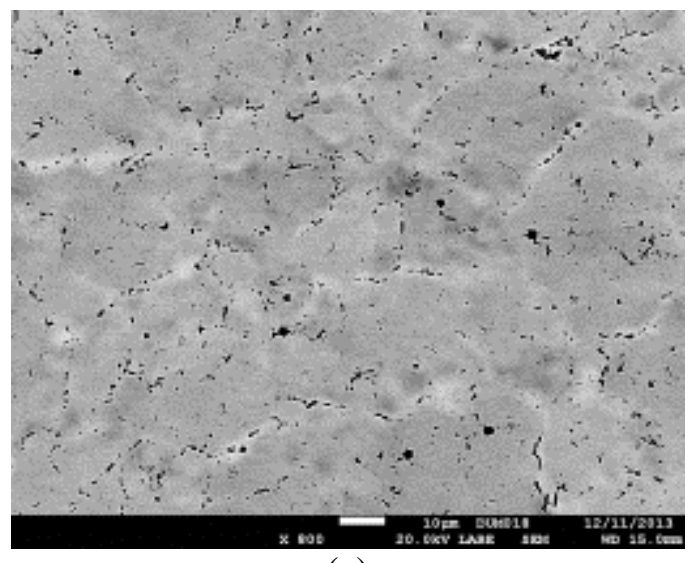

(c)

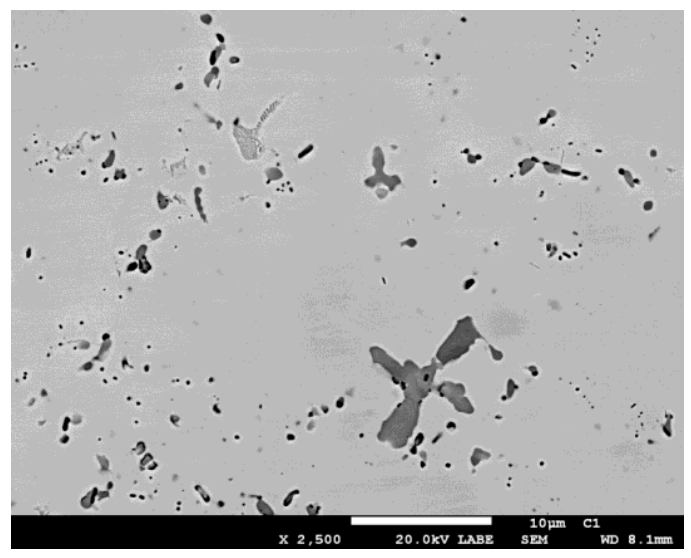

(b)

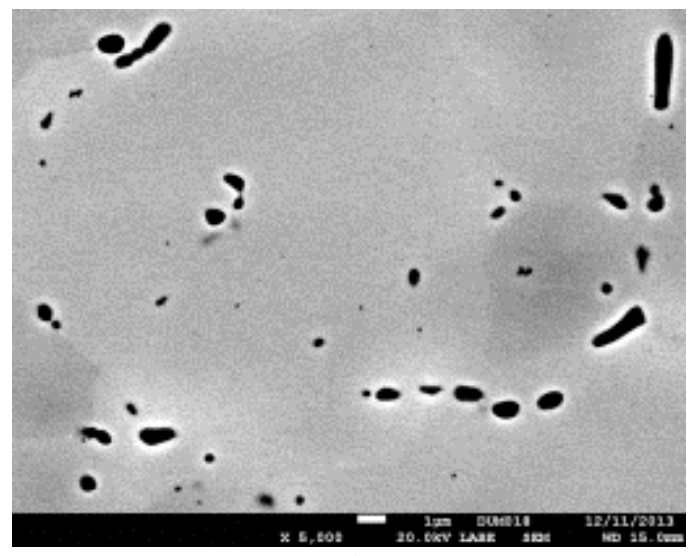

(d)

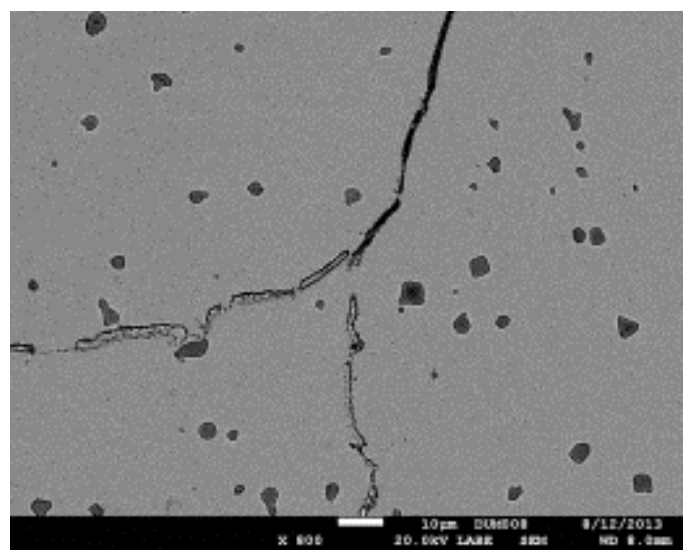

(e)

Fig. 8. BSE-SEM images of the samples after compression testing at $800^{\circ} \mathrm{C}$ : as-cast (a) at $800 \times$, (b) $5000 x$; the samples homogenized at $800^{\circ} \mathrm{C}$ for 24 hours (c) at $800 \times$, (d) $5000 x$; and $1000^{\circ} \mathrm{C}$ for 16 hours (e) at $800 \times$. 


\section{Discussion}

For compression testing below the eutectoid temperature, it was observed that the initial flow stress or the yield stress was primarily a function of the initial grain size. The yield stress/flow stress was lower in the case of the larger grain size samples $(\sim 250 \mu \mathrm{m}$ when homogenized at $1000^{\circ} \mathrm{C}$ for 16 hours) than with the smaller grain size samples (the as-cast samples had a grain size of $\sim 25 \mu \mathrm{m}$ ), whereas the samples heat treated at $800^{\circ} \mathrm{C}$ for 24 hours had intermediate strength and had a grain size of 10-30 $\mu \mathrm{m}$. After initial yield or flow, the samples homogenized at $800^{\circ} \mathrm{C}$ for 24 hours and tested at $500^{\circ} \mathrm{C}$ exhibited a broad peak in the stressstrain curve followed by softening, indicating a dynamic recrystallization phenomenon that is commonly observed in BCC alloys [14]. The absence of the broad stress peak in the samples homogenized at $1000^{\circ} \mathrm{C}$ for 16 hours or in the as-cast structure is likely due to a lack of dynamic recrystallization. This lack of dynamic recrystallization may be due to the coarse grain size [14] for samples heat treated at $1000^{\circ} \mathrm{C}$ for 16 hours and to extensive transformation observed in the as-cast stress-strain behavior.

For compression testing above the eutectoid temperature $\left(650,700\right.$ and $\left.800^{\circ} \mathrm{C}\right)$, the homogenization and corresponding grain size had less impact on the initial flow stress: all flow stresses were nearly identical at a given test temperature. This appears to be explained by the complete recrystallization of the alloy and dissolution of the dendritic structure at 650 and $800^{\circ} \mathrm{C}$ and suppression of the $\alpha$-to- $\gamma^{\prime}$ transformation during heating and cooling. As previously reported [6], strain at temperature appears to accelerate homogenization, as evidenced by the Zcontrast BSE-SEM images. In Fig. 8a, an as-cast sample tested at $800^{\circ} \mathrm{C}$ with total exposure at $800^{\circ} \mathrm{C}$ of less than 25 minutes looks similar to samples shown in Figs. $1 \mathrm{~b}$ and $1 \mathrm{c}$ that were heat 
treated at $800^{\circ} \mathrm{C}$ for 8 and 16 hours, respectively. Homogenization, although not complete, has occurred in much less time with addition of strain.

Compression testing at $650^{\circ} \mathrm{C}$ revealed the most important aspect of homogenization where the test temperature is above any reported time-temperature-transformation curve or eutectoid temperature for U-10 Mo and no transformation $\alpha$ plus $\gamma^{\prime}$ should be expected. However, as shown in Fig. 6a, a lamellar phase has unexpectedly formed (which was not identified in this work). When homogenized at $800^{\circ} \mathrm{C}$ or $1000^{\circ} \mathrm{C}$ and then tested (Figs. $6 \mathrm{c}$ and $6 \mathrm{e}$ ) the lamellar phase is not formed. The elemental constituent that causes this transformation is not known but could be related to the Mo, where $\beta$ phase is possible according to the phase diagram, or by any of the impurities in the alloy. The result indicates that the metastable $\gamma$ phase at or near $650^{\circ} \mathrm{C}$ is not stable with small compositional segregation and that homogenization must be used to prevent formation of additional unpredictable, and likely deleterious, phases.

The initial broad peak in the stress-strain curves in the samples tested above the eutectoid temperature was attributed to possible dynamic recrystallization normally observed in -BCC materials [14]. The dynamic recrystallization is not dramatic, but is observed on grain boundaries after testing, where fine grains in appear in the mottled regions near the grain boundaries like those shown in Figs. 6c and 8c. The negative strain hardening can result in localized instabilities in metalworking and manifest as local dimensional discontinuities, and in extreme cases localizations that result in cracking. In order to avoid this region, metalworking processes should use strains of less than 0.05 or more than 0.15 to make sure that metalworking is performed in a stable flow region (positive strain hardening). 


\section{Conclusions}

This work evaluated the effect of homogenization on the mechanical properties of U-10Mo under compression at elevated temperatures and compared it with the as-cast materials. This new information will be beneficial for further modeling work and fabrication of U-10Mo reactor fuels. It was determined that compression testing $\mathrm{U}-10 \mathrm{Mo}$ at $650^{\circ} \mathrm{C}$ resulted in unexpected lamellar phases, indicating that the process for $\gamma$ decomposition is complex and may be influenced by Mo or impurity segregation. Heat treatment (homogenization) at $800^{\circ} \mathrm{C}$ for 24 hours or $1000^{\circ} \mathrm{C}$ for 16 hours prior to testing completely prevented the transformations. Unstable flow and negative strain hardening were observed between 0.05 and 0.15 strain when tested at temperatures above $650^{\circ} \mathrm{C}$. This softening may be attributed to dynamic recrystallization observed near grain boundaries in as-strained samples. The variation in the compression stressstrain curves was directly correlated with the microstructure upon compression testing. Finegrain-size material has lower flow stress, albeit slight, at temperatures above $650^{\circ} \mathrm{C}$. Heat treatment at $1000^{\circ} \mathrm{C}$ for 16 hours produced almost perfectly plastic flow (work hardening equal to zero), indicating that homogeneous coarse-grain-size structure was more stable.

\section{Acknowledgments}

The current work was supported by the U.S. Department of Energy, National Nuclear Security Administration under Contract DE-AC05-76RL01830. The authors would like to thank Ruby Ermi, Anthony Guzman, Danny Edwards and Alan Schemer-Kohrn of Pacific Northwest National Laboratory for assisting in the mechanical testing and microstructural characterization, and all the other staff directly or indirectly associated with producing the results. The authors also thank Mr. Glenn Moore, Mr. Brady Mackowiak, Mr. Steve Steffler and Mr. Jason 
Schulthess of Idaho National Laboratory for fabrication and supply of the compression test samples.

\section{References}

[1] D. Burkes, D. Senor. The Fuel Fabrication Capability and Uranium-molybdenum Alloy: An Overview. 2014. Presented at the 2014 TMS Annual Meeting \& Exhibition, San Diego, California.

[2] D.E. Dombrowski. Overview of LANL Progress in Process Development, Advanced Characterization Methods and Prototype Fabrication. 2012. In RERTR 2012 - 34th International Meeting On Reduced Enrichment for Research and Test Reactors, Warsaw, Poland.

[3] A. Soulami, C. Lavender, D. Paxton, D. Burkes. Finite Element Analysis of the Rolling of U10Mo Alloy: Parametric Study on Rolling Process Parameters. 2014. Presented at the 2014 TMS Annual Meeting \& Exhibition, San Diego, California.

[4] R.K. McGeary. Development and Properties of Uranium-base Alloys Resistant to Corrosion in High-Temperature Water. 1955. USAEC Report WAPD-127 Part I.

[5] H.A. Saller, W.E. Murr, R.F. Dickerson. Uranium Alloys for High-temperature Application. 1955. Battelle Memorial Institute, Oak Ridge, Tennessee.

[6] V.V. Joshi, E.A. Nyberg, C.A. Lavender, D. Paxton, H. Garmestani, D.E. Burkes. 2013. J. Nucl. Mater. Available online at http://dx.doi.org/10.1016/j.jnucmat.2013.10.065.

[7] V.P. Sinha, P.V. Hegde, G.J. Prasad, G.K. Dey, H.S. Kamath. J. Alloys and Compds. 506 (2010) 253-262. http://dx.doi.org/10.1016/j.jallcom.2010.06.187.

[8] V.P. Sinha, P.V. Hegde, G.J. Prasad, G.K. Dey, H.S. Kamath. J. Alloys and Compds. 491 (2010) 753-760. http://dx.doi.org/10.1016/j.jallcom.2009.11.060. 
[9] V.P. Sinha, G.J. Prasad, P.V. Hegde, R. Keswani, C.B. Basak, S. Pal, G.P. Mishra. J. Alloys and Compds. 473 (2009) 238-244. http://dx.doi.org/10.1016/j.jallcom.2008.05.061.

[10] W.A. Bostrom, E.K. Halteman. The Metastable Gamma Phase in Uranium Base Molybdenum Alloys. 1956. Technical Report WAPD-T-415, Westinghouse Electric Corp., Pittsburgh, PA. Prepared for presentation at 1957 Nuclear Engineering and Science Congress, March 10-16, Philadelphia, PA. http://www.osti.gov/scitech/servlets/purl/4347373.

[11] G.L. Hofman, M.K. Meyer, A.E. Ray. Design of High Density Gamma-Phase Uranium Alloys for LEU Dispersion Fuel Applications. 1998. Presented at the 1998 International Reduced Enrichment for Test Reactor Conference, Sao Paulo, Brazil.

[12] D.J. Edwards, R.M. Ermi, A.L. Schemer-Kohrn, N.R. Overman, C.H. Henager, Jr., D. Burkes, D.J. Senor. Characterization of U-Mo Foils for AFIP-7. 2012. PNNL-21990, Pacific Northwest National Laboratory, Richland, Washington.

[13] A.J. Clarke, R. Field, D. Korzekwa, R. Aikin, D. Hammon, D. Alexander, K. Clarke, A. Kelly, P. Papin, R. McCabe, C. Necker, R. Forsyth, J. Katz, D. Dombrowski. Microstructure Characterization and Processing of U-Mo Alloy Fuels for Nuclear Reactors. 2011. Presented at the 2011 TMS Annual Meeting \& Exhibition, Characterization of Nuclear Reactor Materials and Components with Neutron and Synchrotron Radiation, San Diego, California.

[14] A. Rollett, F.J. Humphreys, G.S. Rohrer, M Hatherly. Recrystallization and Related Annealing Phenomena, Elsevier Science, 2004. 